Osborn, D (2019) The breadth of climate change impacts on biological systems. Emerging Topics in Life Sciences, 3, 107-113. https//doi.org/10.1042/ETLS20180114

\title{
The breadth of climate change impacts on biological systems
}

Dan Osborn, Department of Earth Sciences, University College London, Gower Street, London WC1E 6BT

\begin{abstract}
Human activity is driving climate change. This is affecting and will affect many aspects of life on earth. The breadth of impacts is very wide and covers human, animal and plant health and also the planet's biodiversity and the services that deliver benefits to people from natural capital. Finding solutions to the challenge of climate change will require multi-disciplinary solutions in which the life sciences have a major role to play as this issue of Emerging Topics in Life Sciences indicates. More process and mechanistic knowledge could underpin solutions, or even provide early warning of impacts. Any solutions will need to be developed and deployed in ways that gain and maintain public support.
\end{abstract}

\section{Introduction}

Our planet has developed over billions of years and its surface layers are the result of a long term interplay between living organisms and physical aspects of the planet, including its cyclical motion around our star (see [1] for recent use of such information). From time to time internal and external forces have led to periods where large numbers of the known species have disappeared in the mass extinctions [2]. Some of these may have been triggered by sudden dramatic events (e.g. asteroid strikes). Many periods saw changes that were much more gradual evolutionary processes as conditions on different parts of the planet developed that favoured organisms with different adaptive capacities and tolerance of newly emerging conditions (e.g. [3]. Unpicking the evidence in this area requires multidisciplinary work based on sound life science skills including taxonomy [4]. Life sciences will not be able to provide all the answers. Incorporating inputs from areas such as geography, economics and the social sciences will be essential for finding viable solutions.

\section{So why this issue now?}

Compared to the climatic stability of the last 10,000 years we are in a period of very rapid change with profound consequences (see [5]), driven by humanity's activities. Living organisms have driven change before (such as in the "Great Oxygenation" [6]) but over a much longer time period. Now, humanity's activities are altering the planet's biogeochemical cycles remarkably rapidly - particularly the carbon [7] and nitrogen ones [8].

The issue is needed because humanity must adapt to the level of climate change that is already inevitable and because climate change is already and will further affect so many aspects of life on Earth [9-12]. Importantly, climate change introduces a continually changing dynamic into ecosystems that is entirely unknown during the time in which Civilisation has developed. Adapting successfully means understanding much more about the mechanisms and processes that plants and animals use in relation to temperature, rainfall patterns and biotic interactions across trophic levels including those involving pests and diseases. We also need to understand how nature itself is changing as we know how dependent we are on natural capital derived from Earth system processes 
and how dynamic it's status is [13] due to the services human activities demand from the planet [14 $-16]$.

The carbon cycle is altering because fossil carbon, stored over many millions of years as a result of a combination biological and geological processes, and that has lain dormant for hundreds of millions of years, is being burnt in a matter of some three centuries since the beginning of the Industrial Revolution in the late $18^{\text {th }}$ century. The nitrogen cycle is altering because new technology widely introduced in the mid- $20^{\text {th }}$ century enabled fertilisers to be produced from the nitrogen in the air.

There have been tremendous advantages to society of altering these cycles in terms of supplying energy and food for the growing global population, but the costs are now mounting and solutions to the problems posed need to be found in a very short period of time. In both the carbon and nitrogen case there are unintended consequences of the changes such as widespread pollution of water or warming of the atmosphere and oceans. In neither case do we yet know fully the severity, duration and extent of the impact of altering these cycles. We may also see changes in the frequency and intensity of extreme events especially those involving high rainfall.

In reality, it is impossible to ignore issues linked to the interactions between these two cycles and, for example, the biological ones resulting from falling marine oxygen levels [17]; but these are not foci for this issue.

This themed issue looks at how living organisms are affected by changes in just one of these cycles the carbon one - and how the life sciences are contributing to better understanding the nature of change and the mechanism's and processes that underpin it. It also looks at prospects for solutions.

One issue can only cover a small amount of the overall effort on carbon cycle and climate change research. We concentrate on the contribution to climate change because that is what is affecting the lives of people already and what will continue to affect them well into the future. The effects result primarily from rising temperatures in the atmosphere and in the oceans, changing rainfall patterns and alterations in the $\mathrm{pH}$ of the oceans. However, secondary effects, such as floods, wildfires and droughts are having increasing impacts on people and their communities in many parts of the world.

All this has implications for both terrestrial, surface water and marine life whose geographical ranges, breeding cycles and trophic interactions are being subject to rapid change. It also has implications for the crop, forestry, fishery, pest and disease species which most directly affect humanity. Even with the amount of climate change humanity is already faced with adaptation to these changes is essential $[10,12]$.

\section{Human Health and Wellbeing}

Climate change has considerable implications for human health and wellbeing. Some impacts, such as heat in the open environment and overheating in buildings [18] have well-established knowledge bases. Solutions are in the policy, engineering and construction sectors and not so much in the life sciences, apart from the way green infrastructure could be deployed to help limit heat impacts in urban areas [18]. Humans can acclimatise to higher temperatures but there are limits to this especially as people become older. Emergency management plans to deal with heatwaves are in place in many countries already.

Other aspects of the human health impacts of climate change are more difficult to get to grips with in terms of developing adaptive planning [18]. One such area is that of disease vectors. So, two papers in the issue $[19,20]$ cover a topic with considerable implications for human health and wellbeing. This is because the distribution of and the manner in which disease vectors are able to 
transmit diseases is likely to change. It is essential that we improve our mechanistic and process understanding of vector ecology and transmission. More research is needed in this area if we are to avoid serious impacts on people and agricultural animals, where blue-tongue has already become something of a classic example of the problems faced [21,22]. Although the role of life sciences in combating such situations is well-known (e.g. the use of pesticides and vaccinations) these will need to become more fleet of foot if they are to keep abreast of the changing baseline that comes with rapid climate change especially, for instance, where insect vectors can use adventitious ponds, such as those found in old tyres, to breed. Rising infectiousness with climate change for diseases such as dengue fever is a real concern [23].

The full social costs of climate change impacts on health and the way communities function need to be fully accounted for if flood risks are to be well-managed [18]. This is another example of where expertise from many areas must be combined. For example, flooding not only kills or injuries people directly. There can be long term health consequences for survivors who can be affected not only physically and economically but also psychologically. These impacts can include depression and posttraumatic stress disorder [e.g. 24].

\section{Crops and Forestry}

An increasingly well-researched area is the responses of crop plants. The responses of crop plants to higher temperatures include lower yields in many parts of the world. Earlier findings on cereals have now be joined by information on vegetable and legumes [25] but this is not the only problem we face. The nature of the global food (and other) system(s) will be challenged by climate change [26] even if this can be limited to 1.5 degrees $C$ [27]. Solutions through the life sciences [28] could be controversial involving as they might well accelerated changes to crop plants' genetic material. Even if genetic manipulation as such is not employed but merely enhanced trait selection, care will be needed to ensure the solutions are acceptable to the public, farmers and consumers as these technologies raise issues [29] that may provide lessons for some of the other technologies' that may be needed to combat climate change.

Of immediate concern in many parts of the world are the way in which changing rainfall patterns expose crop plants to problems of drought which is one of those aspects of climate change that could be eased if temperature rises could be kept to 1.5 degrees [30]. One paper in the issue describes various forms of water and heat stress in crop plants together with all important information on process and mechanism [31]. The co-occurrence of drought conditions and high temperatures is a particular concern in some parts of the world [32].

Forestry will not be immune from climate change and although growth of trees may be stimulated by higher levels of atmospheric carbon dioxide there will be, in the near to medium term, trade-offs due to changed rainfall patterns and rising temperatures that may mean forest areas becoming sources rather than sinks of carbon dioxide, especially if the great rainforests in Africa and South America are extensively affected by changes in temperatures, rainfall or land use. This area has already been well researched and the Food and Agriculture Organisation is now confident enough in the findings to be able to issue guidance for policymakers in forestry [33]. Importantly, this report takes a very multidisciplinary approach to getting effective solutions in place. A similar approach to finding solutions for commodity trees also underpins much of the relevant work that has been undertaken for the Ecosystems Services and Poverty Alleviation Programme which contains many examples of how life science knowledge can help people cope more sustainably with environmental pressures and economic necessities [34]. These general lessons should be very valuable in helping deal with climate issues and could be taken up when life science knowledge suggests a solution to a 
societal problem. This would increase the chances of a successful outcome that will improve people's lives.

\section{Land and Marine Biodiversity}

Of course climate change is only one pressure that human activity places on living organisms. Land use changes are another. The way these factors interact is a subject of another paper in this issue [35] and is also covered elsewhere for UK pollinating insects using citizen science approaches [36]. The loss of biodiversity from land use change and the habitat loss that accompanies this is already at very high levels. So much so that the current period is not only one of rapid climate change but also one of rapid biodiversity loss as was recently demonstrated for the case of insects across the globe [37]. Studying biodiversity loss is always challenging and, as exemplified in this issue, some high-level approaches may be needed [38] to test hypotheses or create model frameworks. Such approaches are needed because the outcomes from current levels of biodiversity loss are unclear and efforts to stop or reverse the downward trend have not so far succeeded.

Changes in the oceans are as important as those on land. Here the warming trend is as apparent as is the amount of carbon dioxide that the oceans are absorbing that leads to ocean acidification. The oceans were last as acid as they are now about 55 million years ago. Impacts are already apparent in local fisheries in mostly coastal areas. This is a complex area, as the BIOACID programme reports and publications make clear (https://www.oceanacidification.de). A number of different approaches will be needed to cover the range of situations the world faces. In this issue the use of natural seeps of carbon dioxide to develop a framework for what the oceans might look like in future is set out and put in some overall context [39]. Building this kind of framework of knowledge is one approach to managing a complex problem from a more empirical viewpoint especially when the focus is on a whole ecosystem and the services that are being delivered to people from that ecosystem. Such systems are notoriously difficult to conduct experiments on. This an emerging area of work and the ocean ecosystem will be affected by acidification for many centuries even if emissions of carbon dioxide stopped today. Coastal seas and the open ocean may need separate treatment in order to develop whatever adaptive solutions might be available.

Global warming includes the oceans and headlines (especially about the Great Barrier Reef) have already been made by some major impacts of a warmer ocean on coral systems. Corals bleach when oceans warm [see 40 in this issue for a summary of some key issues] and there is a lively debate in train about what coral bleaching means for corals in the near, medium and long term. Again it can be difficult to separate the impacts of climate change from the impacts of what is in a sense "ocean use change" as human activities such as fishing - or even in the future deep sea mining - also damage corals, especially those already weakened by warming. Work in this area is important as coral ecosystems are vibrant and richly biodiverse habitats. As in the case of ocean acidification, even if emissions stopped now impacts on corals from warmer oceans will continue for some time. These ecosystems may well act as a biological marker for the overall impact of climate change on the oceans if it could be established that they are the most sensitive indicator of warming. Corals, like natural seeps of carbon dioxide, could also be used to develop frameworks to help develop our emerging understanding about impacts on ecosystems. Again, this is an area where we might be able to learn from fossil evidence of past environments.

Some strengthening of projective, if not predictive, capacity is still required in this area and evidence that such approaches are making real progress is given in this issue $[38,41]$.

\section{Sea level rise}


A rising sea-level [42] brings with it the problem of increased amounts of salinized land and other threats to coastal habitats many of which are economically important [43]. Finding crop varieties that can tolerate salinization will help agriculture not only on the coast but also in inland regions where over-irrigation has caused local and regional salinization [44].

The peoples of the small island states may lose their homes if the rate of sea-level rise exceeds the natural process they keep their low lying land above sea-levels, although many interacting factors are involved [45]. The physical and biological processes that are associated with this warrant further study so it can be understood whether some small islands can accrete land fast enough to survive rising seas $[46,47]$.

\section{Limiting climate change through geoengineering}

If countries continue to emit carbon dioxide in line with the current commitments to the Paris Agreement then the world will warm between 3 and 4 degrees $C$ on average (rather more at the poles). This will require global deployment of negative emission technologies - geoengineering technologies [48] - to keep warming down to 1.5 or 2 degrees $C$ on average which is the aim of the Paris Agreement signatories. The life sciences have an important role to play here in assessing and deploying technologies.

Many of the proposed negative emission approaches including BECCs (biomass is grown and burnt under controlled conditions and solid and gaseous residues captured and buried), ocean fertilisation (to increase the uptake of carbon dioxide by marine biota) will need life science knowledge to estimate what is possible and what side effects might ensue or what trade-offs might be entailed $[49,50]$.

Even techniques that might at first be considered purely physical - like limiting solar radiation by injecting sulphur dioxide particulates into the upper atmosphere - will need to be assessed for impacts on biota. It is not so long ago that atmospheric sulphur dioxide began to be managed through the critical loads approach in Europe and in the USA by market mechanisms because it was known to be a pollutant that can have widespread impacts on terrestrial and aquatic biota.

Radical solutions to climate problems could also be envisaged - such as some combination of modifying the rate or effectiveness of photosynthesis so that higher plants or algae took up more carbon dioxide [51, 52]. This might have the added advantage of increased crop yields/biomass provided crop nutritional value were maintained or other products obtained that helped close economic cycles, such as energy production.

The main problem with all geoengineering technologies is that all are in an experimental stage at best or not yet deployed in any real sense. There remain doubts about public acceptability [53 - 55].

\section{Climate feedbacks}

The life sciences also have a role to play in understanding climatic feedbacks. One great uncertainty in the global system is the extent to which the permafrost in the Arctic Circle is likely to respond to the increase in temperatures by releasing methane. Although relatively short lived in the atmosphere, methane is a powerful greenhouse gas that is converted to carbon dioxide. So, methane release from permafrost melt could increase the rate of global warming. Too little is known about the physical and (micro)biological processes involved in permafrost melting [56] and multidisciplinary work is needed to pin down the likely contribution to the methane budget from permafrost and, for that matter, a range of agricultural and industrial practices [57]. We need to know how much of the world's rising levels of methane are coming through environmental biological 
routes (including those under lakes and in marine areas) and how much is coming from agriculture and industry (e.g. though oil and gas exploitation and processing). This is important as methane levels seem to be rising again after a period when they levelled off [58].

\section{Exceeding environmental limits}

The timing of seasonality is one of the most consistent and early signs of the impacts of climate change that has emerged from studies of phenology in species [59-62]. Thus, although this shows the life sciences providing early evidence of impacts, we have been playing catch-up in many ways because of the pace of climate change and have yet to fully recognise the dynamic it is introducing into biological systems. If the life sciences could develop more sensitive measures of change perhaps, biomarkers of climate change based on the kind of improved mechanistic and process understanding illustrated in this issue - then perhaps such measures could be used by policy-makers and decision takers to ensure the planet's systems continue to allow humanity to flourish without needing to adapt excessively. We need to know where the planet's biological limits are and work not to exceed these $[35,38$, and 63$]$. We need sensitive biomarkers of climate change that will provide early warnings of system malfunction. Discovering that the planet's processes may have malfunctioned after the event may be too late [64].

Acknowledgement: I am grateful to a number of colleagues who made suggestions on the content of this article and to the reviewers. I am very appreciative of the time that authors and reviewers of all the articles in this Issue made to fashion and complete contributions. This Issue would not have been completed were it not for the frequent and efficient input from Ben Borthwick and Emma Pettengale in the editorial office. I owe them both many thanks.

\section{References}

[1] Beddow, H. M., Liebrand, D., Wilson, D. S., Hilgen, F. J., Sluijs, A., Wade, B. S., and Lourens, L. J. (2018). Astronomical tunings of the Oligocene-Miocene transition from Pacific Ocean Site U1334 and implications for the carbon cycle, Clim. Past, 14, 255-270, https://doi.org/10.5194/cp-14-2552018.

[2] Stanley, Steven M. (2016) Magnitudes of major marine mass extinctions. Proceedings of the National Academy of Sciences 113, E6325-E6334. DOI: 10.1073/pnas.1613094113

[3] Luciani, V., D'Onofrio, R., Dickens, G.R. and Wade, B.S. (2017). Did photosymbiont bleaching lead to the demise of planktic foraminifer Morozovella at the Early Eocene Climatic Optimum? Paleoceanography, 32, 1115-1136. https://doi.org/10.1002/2017PA003138

[4] Spezzaferri S, Kucera M, Pearson PN, Wade BS, Rappo S, Poole CR, et al. (2015) Fossil and Genetic Evidence for the Polyphyletic Nature of the Planktonic Foraminifera "Globigerinoides", and Description of the New Genus Trilobatus. PLoS ONE 10(5): e0128108.

https://doi.org/10.1371/journal.pone.0128108

[5] Maslin, ETLS-2018-0116CR1

[6] Luo, Genming, Shuhei Ono, Nicolas J. Beukes, David T. Wang, Shucheng Xie and Roger E. Summons (2016) Rapid oxygenation of Earth's atmosphere 2.33 billion years ago. Science Advances, 2, e1600134 DOI: 10.1126/sciadv.1600134

[7] IPCC (2013) Climate Change 2013: The Physical Science Basis. Contribution of Working Group I to the Fifth Assessment Report of the Intergovernmental Panel on Climate Change [Stocker, T.F., D. 
Qin, G.-K. Plattner, M. Tignor, S.K. Allen, J. Boschung, A. Nauels, Y. Xia, V. Bex and P.M. Midgley (eds.)]. Cambridge University Press, Cambridge, United Kingdom and New York, NY, USA, 1535 pp.

[8] Fowler, David, Coyle Mhairi, Skiba Ute, Sutton Mark A., Cape J. Neil, Reis Stefan, Sheppard Lucy J., Jenkins Alan, Grizzetti Bruna, Galloway James N., Vitousek Peter, Leach Allison, Bouwman Alexander F., Butterbach-Bahl Klaus, Dentener Frank, Stevenson David, Amann Marcus , and Voss Maren (2013) The global nitrogen cycle in the twenty-first century. Philosophical Transactions of the Royal Society B: Biological Sciences 368. http://doi.org/10.1098/rstb.2013.0164

[9] IPCC (2014): Climate Change 2014: Impacts, Adaptation, and Vulnerability. Part A: Global and Sectoral Aspects. Contribution of Working Group II to the Fifth Assessment Report of the Intergovernmental Panel on Climate Change [Field, C.B., V.R. Barros, D.J. Dokken, K.J. Mach, M.D. Mastrandrea, T.E. Bilir, M. Chatterjee, K.L. Ebi, Y .O. Estrada, R.C. Genova, B. Girma, E.S. Kissel, A.N. Levy, S. MacCracken, P .R. Mastrandrea, and L.L. White (eds.)]. Cambridge University Press, Cambridge, United Kingdom and New York, NY, USA, 1132 pp.

[10] ASC (2016) UK Climate Change Risk Assessment 2017 Synthesis Report: priorities for the next five years. Adaptation Sub-Committee of the Committee on Climate Change, London. 79 pp.

[11] Warren RF, Wilby RL, Brown K, Watkiss P, Betts RA, Murphy JM, Lowe JA. (2018) Advancing national climate change risk assessment to deliver national adaptation plans. Phil. Trans. R. Soc. A376:20170295. http://dx.doi.org/10.1098/rsta.2017.0295

[12] USGCRP, 2018: Impacts, Risks, and Adaptation in the United States: Fourth National Climate Assessment, Volume II [Reidmiller, D.R., C.W. Avery, D.R. Easterling, K.E. Kunkel, K.L.M. Lewis, T.K. Maycock, and B.C. Stewart (eds.)]. U.S. Global Change Research Program, Washington, DC, USA, 1515 pp. doi: $10.7930 /$ NCA4.2018

[13] Mace, G.M. (2019) The ecology of natural capital accounting. Oxford Review of Economic Policy, 35, 54-67, https://doi.org/10.1093/oxrep/gry023

[14] MA (2005) Living Beyond Our Means: Natural Assets and Human Well-Being - Statement from the Board 24pp https://www.millenniumassessment.org/documents/document.429.aspx.pdf

[15] UK National Ecosystem Assessment (2011) The UK National Ecosystem Assessment: Synthesis of the Key Findings. UNEP-WCMC, Cambridge, 85pp.

[16] UK National Ecosystem Assessment Follow-on (2014) The UK National Ecosystem Assessment: Synthesis of the Key Findings. UNEP-WCMC, Cambridge, 98pp.

[17] Breitburg, Denise, Lisa A. Levin, Andreas Oschlies, Marilaure Grégoire, Francisco P. Chavez, Daniel J. Conley, Véronique Garçon, Denis Gilbert, Dimitri Gutiérrez, Kirsten Isensee, Gil S. Jacinto, Karin E. Limburg, Ivonne Montes, S. W. A. Naqvi, Grant C. Pitcher, Nancy N. Rabalais, Michael R. Roman, Kenneth A. Rose, Brad A. Seibel, Maciej Telszewski, Moriaki Yasuhara, Jing Zhang (2018) Declining oxygen in the global ocean and coastal waters. Science, 359, Issue 6371, eaam7240 DOI: 10.1126/science.aam7240

[18] Kovats, R.S., and Osborn, D., (2016) UK Climate Change Risk Assessment Evidence Report: Chapter 5, People and the Built Environment. Contributing authors: Humphrey, K., Thompson, D., Johns. D., Ayres, J., Bates, P., Baylis, M., Bell, S., Church, A., Curtis, S., Davies, M., Depledge, M., Houston, D., Vardoulakis, S., Reynard, N., Watson, J., Mavrogianni, A., Shrubsole, C., Taylor, J., and Whitman, G. Report prepared for the Adaptation Sub-Committee of the Committee on Climate Change, London. 162 pp. 
[19] Shlomit Paz, ETLS-2018-0124CR1

[20] Thomas, ETLS-2018-0125CR1

[21] Purse, Bethan V., Philip S. Mellor, David J. Rogers, Alan R. Samuel, Peter P. C. Mertens \& Matthew Baylis (2005) Climate change and the recent emergence of bluetongue in Europe. Nature Reviews Microbiology, 3, 171-181.

[22] Samy AM, Peterson AT (2016) Climate Change Influences on the Global Potential Distribution of Bluetongue Virus. PLoS ONE 11(3): e0150489. https://doi.org/10.1371/journal.pone.0150489

[23] Rocklov ETLS-2018-0123CR1

[24] Jermacane, Daiga, Waite, Thomas David, Beck, Charles R., Bone, Angie, Amlôt, Richard, Reacher, Mark, Kovats, Sari, Armstrong, Ben Leonardi, Giovanni, James Rubin, G., Oliver, Isabel (2018). The English National Cohort Study of Flooding and Health: the change in the prevalence of psychological morbidity at year two. BMC Public Health 18, 330 https://doi.org/10.1186/s12889-018-5236-9

[25] Scheelbeek, Pauline F. D.; Frances A. Bird, Hanna L. Tuomisto, Rosemary Green, Francesca B. Harris, Edward J. M. Joy, Zaid Chalabi, Elizabeth Allen, Andy Haines, Alan D. Dangour (2018) Effect of environmental changes on vegetable and legume yields and nutritional quality, Proceedings of the National Academy of Sciences 115, 6804-6809; DOI: 10.1073/pnas.1800442115

[26] Challinor, Andy J., Adger W. Neil, Benton Tim G., Conway Declan, Joshi Manoj and Frame Dave Transmission of climate risks across sectors and borders. Philosophical Transactions of the Royal Society A: Mathematical, Physical and Engineering Sciences 376 https://doi.org/10.1098/rsta.2017.0301

[27] Benton, T.G., Bailey, R., Froggatt, A., King R., Lee, B., Wellesley, L. (2018) Designing sustainable landuse in a $1.5^{\circ} \mathrm{C}$ world: the complexities of projecting multiple ecosystem services from land. Current Opinion in Environmental Sustainability 31:88-95.

[28] Hillhorst ETLS-2018-0139CR1

[29] Myskja B.K. (2016) Naturalness and benefits in the debate on genetic modification. In: Food Futures - Science, Ethics and Cultures (Editors: I. Anna S. Olsson, Sofia M. Araújo and M. Fátima Vieira) pp 523 - 528 https://doi.org/10.3920/978-90-8686-834-6_80

[30] Park, Chang-Eui, Jeong, Su-Jong, Joshi, Manoj, Osborn, Timothy J. Ho, Chang-Hoi, Piao, Shilong, Chen, Deliang, Liu, Junguo, Yang, Hong, Park, Hoonyoung, Kim, Baek-Min, Feng, Song (2018). Keeping global warming within $1.5^{\circ} \mathrm{C}$ constrains emergence of aridification. Nature Climate Change, 8, 70-74. https://doi.org/10.1038/s41558-017-0034-4

[31] Ferguson, ETLS-2018-0105C

[32] Zandalinas, S. I., Mittler, R. , Balfagón, D. , Arbona, V. and Gómez-Cadenas, A. (2018), Plant adaptations to the combination of drought and high temperatures. Physiol Plantarum, 162: 2-12. doi:10.1111/ppl.12540

[33] FAO (2018). Climate change for forest policy-makers - An approach for integrating climate change into national forest policy in support of sustainable forest management - Version 2.0. FAO Forestry Paper no.181. Rome, 68 pp. Licence: CC BY-NC-SA 3.0 IGO. 
[34] Schreckenberg, Kate, Georgina Mace and Mahesh Poudyal (2018) Ecosystem Services for Poverty Alleviation: Trade-offs and Governance. pp 352. Routledge (Taylor \& Francis Group). Ebook ISBN: 9780429016295

[35] Newbold, ETLS-2018-0135CR1

[36] Powney, Gary D., Carvell, Claire, Edwards, Mike, Morris, Roger K. A., Roy, Helen E., Woodcock, Ben A., Isaac, Nick J. B. (2019) Widespread losses of pollinating insects in Britain. Nature Communications 10, 101. https://doi.org/10.1038/s41467-019-08974-9

[37] Sánchez-Bayo, Francisco and Kris A.G. Wyckhuys (2019) Worldwide decline of the entomofauna: A review of its drivers. Biological Conservation, 232, 8-27, https://doi.org/10.1016/j.biocon.2019.01.020

[38] Galbraith ETLS-2019-0042C

[39] Hall-Spencer, ETLS-2018-0117CR1

[40] Crabbe ETLS-2018-0088CR1

[41] Cox ETLS-2018-0113CR1

[42] Hay, Carling C., Morrow, Eric, Kopp, Robert E., Mitrovica, Jerry X. Probabilistic reanalysis of twentieth-century sea-level rise. Nature, 517, 481 - 484. https://doi.org/10.1038/nature14093

[43] R. J. Nicholls et al. (eds.), Ecosystem Services for Well-Being in Deltas, Springer Link pp 593. https://doi.org/10.1007/978-3-319-71093-8

[44] Ismail, Abdelbagi M. and Tomoaki Horie (2017). Genomics, Physiology, and Molecular Breeding Approaches for Improving Salt Tolerance. Annual Review of Plant Biology, 68, 405-434. https://doi.org/10.1146/annurev-arplant-042916-040936

[45] Connell, J. (2016) Last days in the Carteret Islands? Climate change, livelihoods and migration on coral atolls. Asia Pacific Viewpoint, 57, 3-15.

[46] Kench, P.S., D. Thompson, M.R. Ford, H. Ogawa, and R.F. McLean (2015) Coral islands defy sealevel rise over the past century: Records from a central Pacific atoll. Geology; 43 (6): 515-518. doi: https://doi.org/10.1130/G36555.1Nicholls R. J. et al. (eds.), (2018) Ecosystem Services for Well-Being in Deltas, pp 651. Springer Link https://doi.org/10.1007/978-3-319-71093-8

[47] Meriwether, A., W. Wilson, Catherine Forsyth (2018) Restoring near-shore marine ecosystems to enhance climate security for island ocean states: Aligning international processes and local practices. Marine Policy, 93, 284-294. https://doi.org/10.1016/j.marpol.2018.01.018

[48] Royal Society (2009) Geoengineering the climate: Science, governance and uncertainty. Chaired by John Sheperd). Royal Society, London pp 82.

[49] Harper, Anna B., Powell, Tom, Cox, Peter M., House, Joanna, Huntingford, Chris, Lenton, Timothy M., Sitch, Stephen, Burke, Eleanor, Chadburn, Sarah E., Collins, William J., Comyn-Platt, Edward, Daioglou, Vassilis, Doelman, Jonathan C., Hayman, Garry, Robertson, Eddy, van Vuuren, Detlef, Wiltshire, Andy, Webber, Christopher P., Bastos, Ana, Boysen, Lena, Ciais, Philippe, Devaraju, Narayanappa, Jain, Atul K., Krause, Andreas, Poulter, Ben, Shu, Shijie (2018). Land-use emissions play a critical role in land-based mitigation for Paris climate targets. Nature Communications, 9, 2938. https://doi.org/10.1038/s41467-018-05340-z 
[50] Williamson, Phillip, Douglas W.R. Wallace, Cliff S. Law, Philip W. Boyd, Yves Collos, Peter Croot, Ken Denman, Ulf Riebesell, Shigenobu Takeda, and Chris Vivian (2012). Ocean fertilization for geoengineering: A review of effectiveness, environmental impacts and emerging governance. Process Safety and Environmental Protection, 90, 475-488.

https://doi.org/10.1016/j.psep.2012.10.007

[51] McCutcheon, Jenine, Ian M. Power, Anna L. Harrison, Gregory M. Dipple, and Gordon Southam (2014). A Greenhouse-Scale Photosynthetic Microbial Bioreactor for Carbon Sequestration in Magnesium Carbonate Minerals. Environmental Science \& Technology, 48, 9142-9151. DOI: 10.1021/es500344

[52] Furbank, Robert T., W. Paul Quick, Xavier R.R. Sirault (2015). Improving photosynthesis and yield potential in cereal crops by targeted genetic manipulation: Prospects, progress and challenges. Field Crops Research, 182, 19-29, https://doi.org/10.1016/j.fcr.2015.04.009

[53] Stilgoe, J. (2016). Geoengineering as Collective Experimentation. Sci Eng Ethics 22: 851. https://doi.org/10.1007/s11948-015-9646-0

[54] Burns, E.T., J.A.Flegal, D.W.Keith, A.Mahajan, D.Tingley, and G.Wagner (2016). What do people think when the think about solar geoengineering? A review of empirical social science literature, and prospects for future research, Earth'sFuture, 4, 536-542, doi: 10.1002/2016EF000461.

[55] Thomas, G., Pidgeon, N. and Roberts, E. (2018). Ambivalence, naturalness and normality in public perceptions of carbon capture and storage in biomass, fossil energy, and industrial applications in the United Kingdom. Energy Research and Social Science 46, 1-9. doi: 10.1016/j.erss.2018.06.007

[56] Mackelprang, Rachel, Scott R. Saleska, Carsten Suhr Jacobsen, Janet K. Jansson, Neslihan Taş (2016). Permafrost Meta-Omics and Climate Change. Annual Review of Earth and Planetary Sciences 44:1, 439-462. https://doi.org/10.1146/annurev-earth-060614-105126

[57] Schwietzke, Stefan, Owen A. Sherwood, Lori M. P. Bruhwiler, John B. Miller, Giuseppe Etiope, Edward J. Dlugokencky, Sylvia Englund Michel, Victoria A. Arling, Bruce H. Vaughn, James W. C. White \& Pieter P. Tans. (2016). Upward revision of global fossil fuel methane emissions based on isotope database. Nature, $538,88-91$

[58] Bader, W., Bovy, B., Conway, S., Strong, K., Smale, D., Turner, A. J., Blumenstock, T., Boone, C., Collaud Coen, M., Coulon, A., Garcia, O., Griffith, D. W. T., Hase, F., Hausmann, P., Jones, N., Krummel, P., Murata, I., Morino, I., Nakajima, H., O'Doherty, S., Paton-Walsh, C., Robinson, J., Sandrin, R., Schneider, M., Servais, C., Sussmann, R., and Mahieu, E. (2017). The recent increase of atmospheric methane from 10 years of ground-based NDACC FTIR observations since 2005, Atmos. Chem. Phys., 17, 2255-2277. https://doi.org/10.5194/acp-17-2255-2017

[59] Sparks, T., \& Carey, P. (1995). The Responses of Species to Climate Over Two Centuries: An Analysis of the Marsham Phenological Record, 1736-1947. Journal of Ecology, 83(2), 321-329. doi: $10.2307 / 2261570$

[60] Hassall, C., Thompson, D. J., French, G. C. and Harvey, I. F. (2007), Historical changes in the phenology of British Odonata are related to climate. Global Change Biology, 13: 933-941. doi: 10.1111/j.1365-2486.2007.01318.x 
[61] Jochner, S., Sparks, T.H., Laube, J. et al. (2016) Can we detect a nonlinear response to temperature in European plant phenology? Int J. Biometeorol 60: 1551.

https://doi.org/10.1007/s00484-016-1146-7

[62] Tryjanowski, P., Sparks, T.H., Blecharczyk, A. et al. (2018). Changing Phenology of Potato and of the Treatment for its Major Pest (Colorado Potato Beetle) - A Long-term Analysis. Am. J. Potato Res. 95: 26. https://doi.org/10.1007/s12230-017-9611-3

[63] Newbold, Tim, Lawrence N. Hudson, Andrew P. Arnell, Sara Contu, Adriana De Palma, Simon Ferrier, Samantha L. L. Hill, Andrew J. Hoskins, Igor Lysenko, Helen R. P. Phillips, Victoria J. Burton, Charlotte W. T. Chng, Susan Emerson, Di Gao, Gwilym Pask-Hale, Jon Hutton, Martin Jung, Katia Sanchez-Ortiz, Benno I. Simmons, Sarah Whitmee, Hanbin Zhang, Jörn P. W. Scharlemann, Andy Purvis (2016). Has land use pushed terrestrial biodiversity beyond the planetary boundary? A global assessment. Science 353, 288-291 DOI: 10.1126/science.aaf2201 288-291

[64] Hughes, Terry P., Kerry, James T., Baird, Andrew H., Connolly, Sean R., Chase, Tory J., Dietzel, Andreas, Hill, Tessa, Hoey, Andrew S., Hoogenboom, Mia O., Jacobson, Mizue, Kerswell, Ailsa, Madin, Joshua S., Mieog, Abbie, Paley, Allison S., Pratchett, Morgan S., Torda, Gergely, Woods, Rachael M. (2019). Global warming impairs stock-recruitment dynamics of corals. Nature, 1476 4687. https://doi.org/10.1038/s41586-019-1081-y 